\title{
Natural reduced water suppressed anxiety and protected the heightened oxidative stress in rats
}

This article was published in the following Dove Press journal:

Neuropsychiatric Disease and Treatment

8 September 2017

Number of times this article has been viewed

Koji Masuda

Yoshihiro Tanaka

Masayuki Kanehisa

Taiga Ninomiya

Ayako Inoue

Haruka Higuma

Chiwa Kawashima

Mari Nakanishi

Kana Okamoto

Jotaro Akiyoshi

Department of Neuropsychiatry, Oita University Faculty of Medicine, Hasama-Machi, Oita, Japan
Correspondence: Jotaro Akiyoshi Department of Neuropsychiatry, Oita University Faculty of Medicine, HasamaMachi, Oita 879-5593, Japan

$\mathrm{Tel}+8$ I 975865823

Fax +8I 975493583

Email akiyoshi@oita-u.ac.jp
Background: In Japan, the effects of reduced water, such as hydrogen-rich electrolyzed reduced water and natural reduced water, like Hita Tenryosui water ${ }^{\circledR}$, have been examined. The purpose of the present study was to identify the role of natural reduced water in anxiety and blood biochemical analysis.

Materials and methods: Natural reduced water and distilled water were administered to rats for 180 consecutive days, and their effect on anxiety-like behavior and depression was examined by using elevated plus maze, light/dark, forced swimming, and conditioned fear tests. Before and after administration of natural reduced or distilled water, we performed blood and urine analyses.

Results: Natural reduced water exhibited anxiolytic-like effects in the conditioned fear and elevated plus maze tests. The mean levels of urinary 8-hydroxy-2'-deoxyguanosine (8-OHdG) in the natural reduced water were significantly lower than the distilled water group. Natural reduced water group also showed decrease in blood-urea nitrogen levels compared with the distilled water group.

Conclusion: These results indicate that natural reduced water may decrease anxiety-related behaviors and prevent heightened oxidative stress.

Keywords: urea nitrogen, depression, Hita Tenryosui, conditioned fear, elevated plus maze, 8-OHdG

\section{Introduction}

Water is very important for our health and physiological functions. For many years, global environmental pollution has induced a major social problem. Drinking contaminated water may cause serious illnesses and diseases. ${ }^{1}$

Some reports showed the functional roles of reduced water in Japan. ${ }^{2}$ Naturally and electrochemically reduced water can scavenge reactive oxygen species (ROS) in cultured cells. Reduced water is reported to have preventive and therapeutic effects on oxidative stress-related diseases, such as diabetes, cancer, arteriosclerosis, and neurodegenerative diseases. The active substances in reduced water have been reported to be hydrogen, mineral nanoparticles, and mineral nanoparticle hydrides.

The natural reduced water used in our study is mineral water sanitarily collected from a depth of about 1,000 $\mathrm{m}$ at the collection site. Aquaporin water channels are found in a subset of epithelia with a 10- to 100 -fold higher capacity for water permeation than in normal epithelia. ${ }^{3}$ In addition, it is believed that aquaporin influences activation of natural killer cells. ${ }^{4}$ During the 5 th Aquaporins International Conference held in 2007, natural reduced water was considered to be an official beverage; at the citizens public forum, a research case study on cell activation was presented. ${ }^{5}$ Anxiety may damage the normal function of the neuroendocrine system and the immune system that impairs the balance of the oxidation/inflammatory. ${ }^{6}$ The 8 -hydroxy- $2^{\prime}$-deoxyguanosine 
(8-OHdG), an oxidized nucleoside of DNA, is the most frequently detected and studied DNA. ${ }^{7}$ 8-OHdG is excreted in the urine upon DNA repair. The study has shown that urinary 8-OHdG not only is a biomarker of generalized, cellular oxidative damage but might also be a risk factor for cancer, atherosclerosis, and diabetes. ${ }^{8}$ Urinary $8-\mathrm{OHdG}$ is noninvasive and technically less involved and can be measured with a simple enzyme-linked immunosorbent assay (ELISA). ${ }^{9}$ The purpose of the present study was to identify the role of natural reduced water in anxiety, depression, and oxidative stress.

\section{Materials and methods}

\section{Animals}

Male Wistar rats (Kyudo Co., Ltd., Fukuoka, Japan), 8 weeks of age, were divided into two groups $(n=20$ animals per treatment group). One group (control group) was administered distilled water (Milli Q; EMD Millipore, Billerica, MA, USA), and the second group (natural reduced water group) was administered Hita Tenryosui water ${ }^{\circledR}$ (Hita Tenryosui Co., Oita, Japan). The mean body weight of rats was $325 \pm 23.1 \mathrm{~g}$ in the control group and $318 \pm 22.2 \mathrm{~g}$ in the natural reduced water group. Each pair of rats was placed in one cage, and ad libitum access to food and water was provided. Cages were $15 \mathrm{~cm}$ high with a floor size of $22 \times 35 \mathrm{~cm}$. The room was controlled with a constant 12-h light/12-h dark cycle with lights on at $18: 00 \mathrm{~h}$, at a temperature of $22^{\circ} \mathrm{C}-23^{\circ} \mathrm{C}$ and $50 \%-60 \%$ humidity. Each experiment was conducted between 9:00 and 14:00 h during the dark cycle. All experiments were approved by the Animal Ethics Committee of Oita University Faculty of Medicine. We conducted all experiments based on the Regulations for Animal Experiments and Related Activities at Oita University.

\section{Behavioral testing}

Affective-like behavior was determined using elevated plus maze test during light/dark cycles or 20 rats for each behavioral test. We conducted the behavior tests at the end of the experiment.

\section{Elevated plus maze test}

The elevated plus maze test was used to investigate anxietyrelated behavior in rats. The apparatus used in this experiment was constructed of nontransparent plastic, two opposite open arms $(50 \times 10 \mathrm{~cm})$ without side walls and two enclosed arms $(50 \times 10 \mathrm{~cm})$ with walls that were $40 \mathrm{~cm}$ high. Each arm extended in an overall cross shape from a central platform $(10 \times 10 \mathrm{~cm})$. The plus maze was elevated $50 \mathrm{~cm}$ above the floor. Red lights $(60 \mathrm{~W})$ were placed $1 \mathrm{~m}$ above the maze for lighting. Individual rats ( $\mathrm{n}=20$ in each group) were placed on the platform facing an open arm, and they were immediately left alone in the test room and observed for 5 min with a camcorder. Behavioral data were recorded and scored on the basis of the following activity: the number of entries into the closed arms. Rats tend to prefer the closed arm when they feel strong anxiety. ${ }^{10}$

\section{Light/dark test}

This apparatus consisted of two boxes $(23 \times 27 \mathrm{~cm}$ floor, $27 \mathrm{~cm}$ high walls). Each box had a fixed white or red lamp $(60 \mathrm{~W})$ as its light source located $17 \mathrm{~cm}$ above the box. The boxes were connected by a $6 \mathrm{~cm}$-high semicircular opening that allowed the rats to move freely between the two compartments. Individual rats ( $\mathrm{n}=15$ for each group) were placed, facing the opening, on the center of the compartment with the fixed white lamp (light box), and they were immediately left alone in the test room and observed for $5 \mathrm{~min}$ with a camcorder. Rat behavioral data were recorded for the item: total time spent in the light room. In this model, entries into the black room are believed to indicate anxiety-like behavior. ${ }^{10}$

\section{Forced swimming}

Individual rats ( $\mathrm{n}=20$ for each group) were placed in a column-shaped glass case (diameter $22 \mathrm{~cm}$, height $40 \mathrm{~cm}$ ) that contained water at a height of $25 \mathrm{~cm}$, and they were immediately left alone and observed for $15 \mathrm{~min}$ with a camcorder. In this model, cessation of swimming behavior (ie, becoming immobile) was believed to indicate depression-like behavior. To control general exploratory activity, the rats were placed in a standard apparatus (36 cm high, $30 \mathrm{~cm}$ wide, and $30 \mathrm{~cm}$ long) after administration of waters was determined by the number of infrared photobeam breaks in a 2 -h period.

\section{Conditioned fear test}

On day 1 of fear conditioning, each rat was individually subjected to $5 \mathrm{~min}$ of inescapable electric foot shocks (10 shocks of 1 -s duration and $2 \mathrm{~mA}$ intensity, with 40-s intervals in a chamber with a grid floor $[31 \times 30 \times 25 \mathrm{~cm}])$. Twenty-four hours after the foot shock, the rats were again placed in the shock chamber and observed for 5 min without shocks. During the 5-min observation period, freezing behavior was recorded using a video camera. For every $10 \mathrm{~s}$, behavior was classified as either freezing or active. Freezing was defined as the absence of any observable movement of the body and/ or vibrissae, besides involuntary respiratory movements. 


\section{Forced swimming test}

The procedure used has previously been described ${ }^{11}$ and was very similar to that described for the Porsolt test. ${ }^{12}$ In the forced swimming test, the rats were placed in a cylindrical container (height $400 \mathrm{~mm}$, diameter $200 \mathrm{~mm}$ ) filled with water $\left(25^{\circ} \mathrm{C}\right.$; level $250 \mathrm{~mm}$ above the bottom) for $15 \mathrm{~min}$. On day 2, the procedure was repeated, with rats kept in water for $5 \mathrm{~min}$. The water in the cylinders was changed after every trial. On day 2 , motor activity was measured using an apparatus with an infrared sensor (Neuroscience Inc., Tokyo, Japan) that detected thermal radiation from the animals. The movements of the rats were digitized and fed into a computer (Mac Lab v3.5).

\section{General locomotor activity}

We measured general locomotor activity of rats by means of infrared photobeam breaks for $3 \mathrm{~h}$ (Activity Sensor Model, NS-AS01, Neuroscience Inc.), because locomotion influences exploratory activity. The apparatus was $36 \mathrm{~cm}$ in height and the floor size was $30 \times 30 \mathrm{~cm}$. The data were stored in a PowerLab system (AD Instruments, Colorado Springs, CO, USA).

\section{Blood analyses}

Before and at the end of the experiment, the following were measured: plasma blood-urea nitrogen (BUN), total cholesterol, triglyceride, high-density lipoprotein (HDL)cholesterol, low-density lipoprotein (LDL)-cholesterol, total-bilirubin, direct-bilirubin, AST, ALT, uric acid, creatinine, glucose, total protein, and albumin. ${ }^{13}$ All data were represented as mean $\pm \mathrm{SD}$.

\section{Urine analyses}

After administration of natural reduced water group or distilled water, the urinary $8-\mathrm{OHdG}$ was measured. Immediately after collection, urine samples were stored at $-80^{\circ} \mathrm{C}$ in the dark until assayed. The level of urinary $8-\mathrm{OHdG}$ was measured with a MICRO Plate READER Model 680 (Bio-Rad Laboratories Inc., Hercules, CA, USA) by using an 8-OHdG Check ELISA kit, which contains the anti-8-OHdG monoclonal antibody N45.1 (Japan Institute for the Control of Aging). ${ }^{14}$ The results of 8-OHdG were corrected for the urinary concentration of creatinine, which was determined with an Accuras Auto CRE (Shino test).

\section{Statistical analysis}

The results were analyzed using Mann-Whitney $U$ test for the black and white box test and the elevated plus maze test, and two-factor analysis of variance (ANOVA) was for the open-field test.

\section{Results \\ Elevated plus maze test}

Time spent in the closed arm of the elevated plus maze was significantly decreased in the natural reduced water group (22.0 $\pm 8.4 \mathrm{~s})$, compared with the distilled water group $(28.2 \pm 9.0 \mathrm{~s})(p<0.05)$ (Figure 1).

\section{Conditioned fear stress test}

In conditioned fear stress test, the freezing time of natural reduced water $(21.6 \pm 4.5 \mathrm{~s})$ was significantly decreased, compared with the distilled water group $(25.3 \pm 4.6 \mathrm{~s})$ $(p<0.01)$ (Figure 2).

\section{Black and white box test}

No significant deference between the natural reduced water group $(287.9 \pm 7.7 \mathrm{~s})$ and the distilled water group $(291.8 \pm 5.4 \mathrm{~s})$ was observed in the black and white box test $(p=0.41)$.

\section{Forced swimming test}

No significant difference between the natural reduced water group $(128.9 \pm 36.5 \mathrm{~s})$ and the distilled water group $(127.9 \pm 28.1 \mathrm{~s})$ was observed in the forced swimming test $(p=0.21)$.

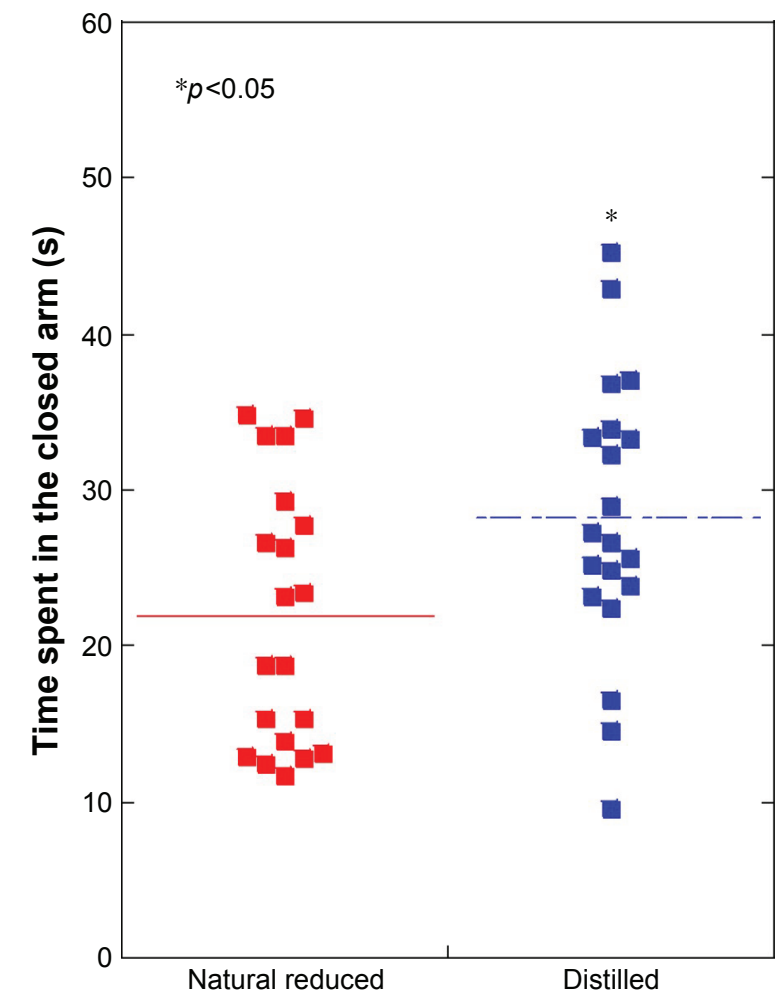

Figure I Elevated plus maze test: time spent in the closed arm was significantly decreased in the natural reduced water group, compared with the distilled water group $(p<0.05)$.

Notes: $\mathrm{N}=20$ per group. ${ }^{*} p<0.05$. Line is presented as mean. 


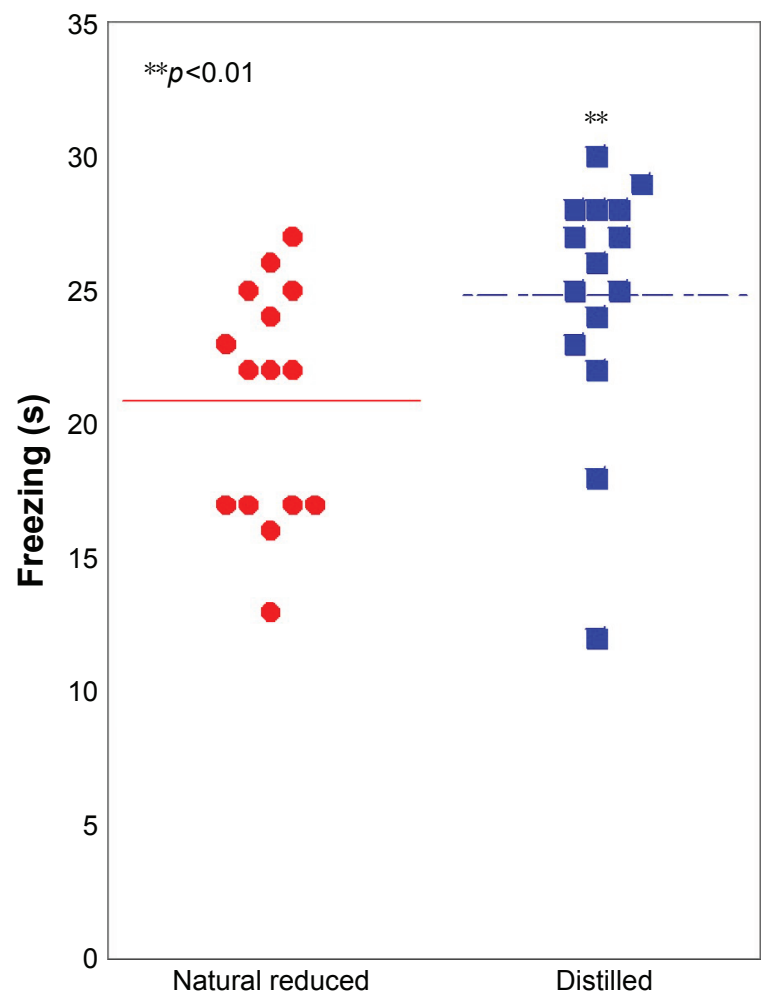

Figure 2 Conditioned fear stress test: the freezing time was significantly decreased in the natural reduced water group, compared with the distilled water group $(p<0.01)$. Notes: $\mathrm{N}=20$ per group. $* * p<0.0$ I. Line is presented as mean.

\section{Open-field behavior}

No significant difference between the natural reduced water group and the distilled water group was observed in the open field test $(F[1.338]=0.91, p=0.35)$.

\section{Effect on 8-OHdG}

The mean levels of urinary 8 -OHdG between the natural reduced water group and the distilled water group were 18.6 \pm 16.4 and $35.9 \pm 17.7 \mu \mathrm{g} / \mathrm{g}$ creatinine, respectively (Figure 3 ). The mean levels of urinary $8-\mathrm{OHdG}$ in the natural reduced water were significantly lower than the distilled water group.

\section{Effect on BUN}

The natural reduced water group (22.9 \pm 9.3 ) showed a decrease in BUN levels compared with the distilled water group (28.2 \pm 9.0 ) (Figure 4). However, there were no differences between both groups in terms of total cholesterol, triglyceride, HDL-cholesterol, LDL-cholesterol, total-bilirubin, direct-bilirubin, AST, ALT, uric acid, creatinine, glucose, total protein, and albumin.

\section{Discussion}

Natural reduced water decreased conditioned fear stress in rats. Conditioned fear stress represents one of the most

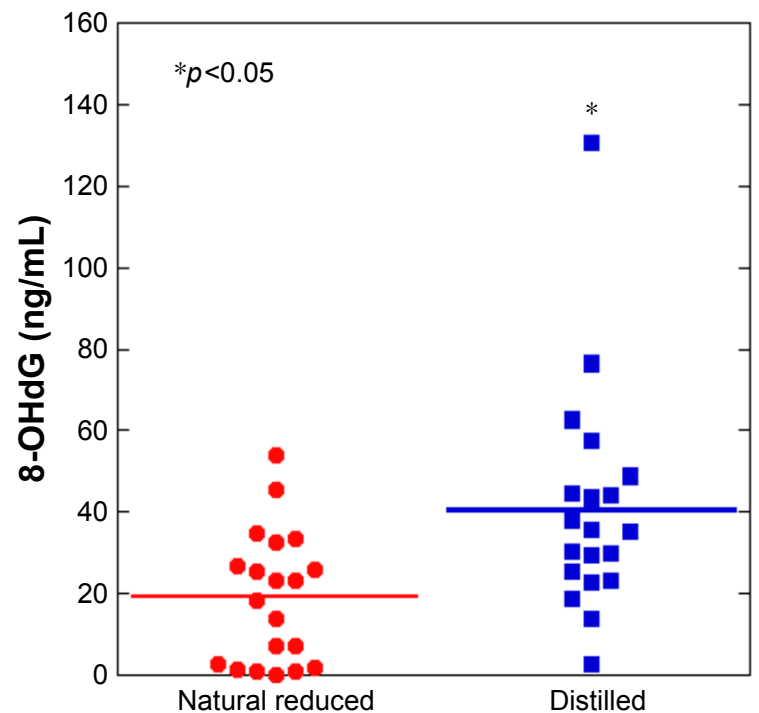

Figure 3 The natural reduced water group showed a decrease in urinary 8-hydroxy-2'-deoxyguanosine (8-OHdG) levels compared with the distilled water group $(p<0.05)$.

Notes: $\mathrm{N}=20$ per group. $* p<0.05$. Line is presented as mean.

Abbreviation: 8-OHdG, 8-hydroxy-2'-deoxyguanosine.

effective and modest forms of producing aversive learning, which was historically associated with one of the main causes of anxiety. ${ }^{15}$ This kind of stress was reported to be associated with increased free radical production, ${ }^{16}$ which natural reduced water may suppress. Defensive freezing behavior was believed to be one of the most reliable measures of conditioned fear stress.

The mean levels of urinary $8-\mathrm{OHdG}$ in the natural reduced water were significantly lower than the distilled water group. Antioxidative water, like natural reduced

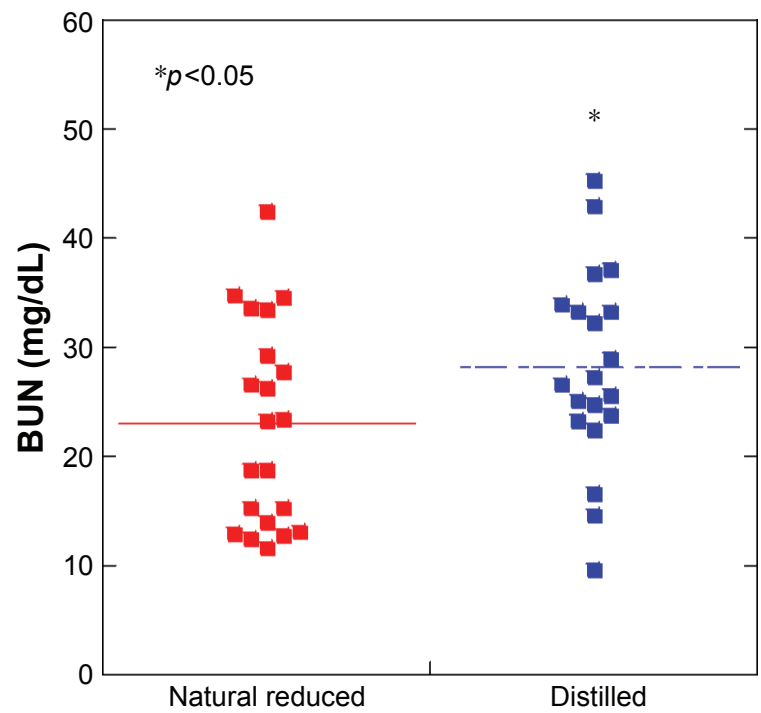

Figure 4 The natural reduced water group showed a decrease in blood-urea nitrogen (BUN) levels compared with the distilled water group $(p<0.05)$

Notes: $\mathrm{N}=20$ per group. ${ }^{*} p<0.05$. Line is presented as mean.

Abbreviation: BUN, blood-urea nitrogen. 
water, could scavenge intracellular ROS in hamster pancreatic $\beta$ cells. ${ }^{17}$ In addition, natural killer cell activities in healthy volunteers drinking natural reduced water significantly improved. ${ }^{5}$ Natural reduced water protects against alloxan (ALX)-induced $\beta$-cell apoptosis and prevents the development of ALX-induced diabetes mellitus in experimental animals by regulating ALX-derived ROS generation and increasing the level of antioxidative enzymes. ${ }^{18}$ The practice of yoga ameliorates the mental state by lowering the levels of anxiety, depression, and anger. ${ }^{19}$ The urine $8-\mathrm{OHdG}$ concentration showed a trend toward being lower in the long-term yoga group in comparison with the control group..$^{20}$

The natural reduced water group showed a decreased level of BUN compared with the distilled water group. Oxidants generated because of a variety of biochemical reactions in the body can damage all biological molecules, such as DNA, RNA, cholesterol, lipids, carbohydrates, proteins, and antioxidants. ${ }^{21}$ The level of BUN in the body indicates the appropriate functioning of the kidney, and as antioxidant levels deteriorate, oxidative stress and free radical damage are increased. Natural reduced water may protect against these kinds of damage. In 2015, Chaturvedi et al. ${ }^{22}$ reported that increased oxidative stress and free radical toxicity in dementia patients caused membrane damage. In addition, serum BUN level on admission was associated with an increased burden of coronary artery disease during cardiac catheterization..$^{23}$ Further studies are required to examine the association between BUN and somatic and psychiatric diseases.

In conclusion, these results indicate that natural reduced water may decrease anxiety-related behaviors and prevent heightened oxidative stress.

\section{Conclusion}

Natural reduced water encompasses a novel and attractive field of study that may link mineral water intake with human health and therapeutic strategies for some lifestyle-related anxiety disorders.

\section{Acknowledgments}

We thank Hita Tenryosui Co. (Oita, Japan) for providing Hita Tenryosui water. This work was supported by a Grantin-Aid for Scientific Research from the Ministry of Education, Science, Sports, and Culture of Japan (C26462159). The funding body did not affect the design of the study and collection, analysis, and interpretation of data and in writing the manuscript.

\section{Author contributions}

All authors contributed toward data analysis, drafting and critically revising the paper and agree to be accountable for all aspects of the work.

\section{Disclosure}

Dr Akiyoshi has received unrestricted research grants from Hita Tenryosui Co., Ltd. The authors report no other conflicts of interest in this work.

\section{References}

1. Imtiaz M, Rizwan MS, Xiong S, et al. Vanadium, recent advancements and research prospects: a review. Environ Int. 2015;80:79-88.

2. Shirahata S, Hamasaki T, Teruya K. Advanced research on the health benefit of reduced water. Trends Food Sci Tech. 2012;23:124-131.

3. Agre P, King LS, Yasui M, et al. Aquaporin water channels - from atomic structure to clinical medicine. J Physiol. 2002;542(pt 1):3-16.

4. Vincent T, Saikali P, Cayrol R, et al. Functional consequences of neuromyelitis optica-IgG astrocyte interactions on blood-brain barrier permeability and granulocyte recruitment. J Immunol. 2008;181(8):5730-5737.

5. Kitagawa Y, Liu C, Ding X. The influence of natural mineral water on aquaporin water permeability and human natural killer cell activity. Biochem Biophys Res Commun. 2011;409(1):40-45.

6. Vida C, Gonzalez E, De la Fuente M. Increase of oxidation and inflammation in nervous and immune systems with aging and anxiety. Curr Pharm Des. 2014;20(29):4656-4678.

7. Espinosa O, Jiménez-Almazán J, Chaves FJ, et al. Urinary 8-oxo-7,8dihydro-2'-deoxyguanosine (8-oxo-dG), a reliable oxidative stress marker in hypertension. Free Radic Res. 2007;41(5):546-554.

8. Cooke MS, Evans MD, Burd RM, et al. Induction and excretion of ultraviolet-induced 8-oxo-2'-deoxyguanosine and thymine dimers in vivo: implications for PUVA. J Invest Dermatol. 2001;116(2):281-285.

9. Chiou CC, Chang PY, Chan EC, Wu TL, Tsao KC, Wu JT. Urinary 8-hydroxydeoxyguanosine and its analogs as DNA marker of oxidative stress: development of an ELISA and measurement in both bladder and prostate cancers. Clin Chim Acta. 2003;334(1-2):87-94.

10. Tanaka Y, Akiyoshi J, Kawahara Y, et al. Infrared radiation has potential antidepressant and anxiolytic effects in animal model of depression and anxiety. Brain Stimul. 2011;4(2):71-76.

11. Detke MJ, Johnson J, Lucki I. Acute and chronic antidepressant drug treatment in the rat forced swimming test model of depression. Exp Clin Psychopharmacol. 1997;5(2):107-112.

12. Porsolt RD, Bertin A, Jalfre M. Behavioral despair in mice: a primary screening test for antidepressants. Arch Int Pharmacodyn Ther. 1977; 229(2):327-336

13. Goldberg DM, Spooner RJ. Methods of enzymatic analysis. In: Bergmayer HU, editor. Methods of Enzymatic Analysis (3rd ed). New Jersey: Verlag Chemie; 1983:258-265.

14. Miyaoka T, Ieda M, Hashioka S, et al. Analysis of oxidative stress expressed by urinary level of biopyrrins and 8-hydroxydeoxyguanosine in patients with chronic schizophrenia. Psychiatry Clin Neurosci. 2015;69(11):693-698.

15. Landeira-Fernandez J. Context and Pavlovian conditioning. Braz J Med Biol Res. 1996;29(2):149-173.

16. Hassan W, Gomes Vde C, Pinton S, Batista Teixeira da Rocha J, Landeira-Fernandez J. Association between oxidative stress and contextual fear conditioning in Carioca high- and low-conditioned freezing rats. Brain Res. 2013;1512:60-67.

17. Li Y, Nishimura T, Teruya K, et al. Protective mechanism of reduced water against alloxan-induced pancreatic beta-cell damage: scavenging effect against reactive oxygen species. Cytotechnology. 2002; 40(1-3):139-149. 
18. Li Y, Hamasaki T, Teruya K, et al. Suppressive effects of natural reduced waters on alloxan-induced apoptosis and type 1 diabetes mellitus. Cytotechnology. 2012;64(3):281-297.

19. Lavey R, Sherman T, Mueser KT, Osborne DD, Currier M, Wolfe R. The effects of yoga on mood in psychiatric inpatients. Psychiatr Rehabil J. 2005;28(4):399-402.

20. Yoshihara K, Hiramoto T, Sudo N, Kubo C. Profile of mood states and stress-related biochemical indices in long-term yoga practitioners. Biopsychosoc Med. 2011;5(1):6.

21. Sultana R, Perluigi M, Newman SF, et al. Redox proteomic analysis of carbonylated brain proteins in mild cognitive impairment and early Alzheimer's disease. Antioxid Redox Signal. 2010;12(3):327-336.
22. Chaturvedi A, Natarajan A, Sharma V, et al. Association of age related severity in oxidative stress and blood urea nitrogen levels in patients with dementia. A coastal Karnataka study. Asian J Biomed Pharm Sci. 2015;5:6-10.

23. Ostfeld R, Spinelli M, Mookherjee D, et al. The association of blood urea nitrogen levels and coronary artery disease. Einstein J Biol Med. 2010;26:3-7.

\section{Publish your work in this journal}

Neuropsychiatric Disease and Treatment is an international, peerreviewed journal of clinical therapeutics and pharmacology focusing on concise rapid reporting of clinical or pre-clinical studies on a range of neuropsychiatric and neurological disorders. This journal is indexed on PubMed Central, the 'PsycINFO' database and CAS, and is the official journal of The International Neuropsychiatric Association (INA). The manuscript management system is completely online and includes a very quick and fair peer-review system, which is all easy to use. Visit http://www.dovepress.com/testimonials.php to read real quotes from published authors.

Submit your manuscript here: http://www.dovepress.com/neuropsychiatric-disease-and-treatment-journal 